\title{
LA TRASCENDENCIA DE LA DIGNIDAD HUMANA EN EL PROCESO DE RECONOCIMIENTO INTERNACIONAL DE LOS DERECHOS LABORALES
}

\author{
THE TRANSCENDENCE OF HUMAN DIGNITY IN THE PROCESS OF \\ INTERNATIONAL RECOGNITION OF LABOR RIGHTS
}

Marcio Morena Pinto*

\begin{abstract}
Resumen: La dignidad es una característica intrínseca y común a todos los seres humanos. A partir de esta premisa, el presente artículo pretende realizar un abordaje histórico del proceso de reconocimiento jurídico internacional de los derechos humanos laborales, con la finalidad de comprender y justificar la construcción de un verdadero núcleo duro de derechos que fueron siendo cristalizados a lo largo del tiempo en instrumentos normativos de protección a los trabajadores. En este contexto, por su incuestionable estatus de universalidad, han sido analizados la Declaración Universal de los Derechos Humanos, a pesar de su carácter no vinculante, y el Pacto Internacional de Derechos Económicos, Sociales y Culturales, que consolidaron un catálogo de derechos mínimos para la mejoría de las condiciones de vida de los trabajadores en todo el mundo, preservando, de esa manera, su inherente dignidad.
\end{abstract}

Palabras-clave: Derechos Humanos; Derechos Laborales; Dignidad de la persona humana; Declaración Universal de los Derechos Humanos; Pacto Internacional de los Derechos Económicos, Sociales y Culturales.

Resumo: A dignidade é uma característica intrínseca e comum a todos os seres humanos. A partir dessa premissa, o presente artigo busca realizar uma abordagem histórica do processo de reconhecimento jurídico internacional dos direitos humanos dos trabalhadores, a fim de entender e justificar a construção de um verdadeiro núcleo duro de direitos que foram sendo cristalizado ao longo do tempo em instrumentos normativos de proteção aos trabalhadores. Neste contexto, pelo seu inquestionável estatus de universalidade, foram analisados a Declaração Universal dos Direitos Humanos, apesar de seu carácter não-vinculante, e o Pacto Internacional sobre Direitos Económicos, Sociais e Culturais, que consolidou um rol de direitos mínimos para a melhoria das de vida condições dos trabalhadores de todo o mundo, preservando, destarte, a sua inerente dignidade.

Palaras-chave: Direitos Humanos; Direito do Trabalho; Dignidade da pessoa humana; Declaração Universal dos Direitos Humanos; Pacto Internacional de Direitos Econômicos, Sociais e Culturais.

Abstract: Dignity is an intrinsic and common characteristic to all human beings. From this premise, this article aims to make a historical approach to the process of international legal recognition of labor rights, in order to understand and justify the construction of a true hard core of rights crystallized in policy instruments on protection of workers. In this context, because of its unquestioned status of universality, the Universal Declaration of Human Rights, despite its non-binding, and the International Covenant on Economic, Social and Cultural

\footnotetext{
* Doutor em Direito Internacional pela Universidade de Barcelona (Espanha). Mestre e bacharel em Filosofia pela Faculdade de Filosofia, Letras e Ciências Humanas da Universidade de São Paulo (FFLCH-USP). Máster em Estudos Internacionais pela Universidade de Barcelona. (Espanha). Especialista em Direito Empresarial pela Universidade Presbiteriana Mackenzie (UPM). Bacharel em Direito pela Universidade Presbiteriana Mackenzie (UPM). Foi bolsista da FAPESP, da CAPES e da Fundação Carolina (Espanha). Professor universitário e advogado. E- mail: marciomorena@hotmail.com
} 
Rights have been analyzed, which consolidated a group of minimum rights for the improvement of living conditions of workers throughout the world, preserving, thus, their inherent dignity.

Keywords: Human rights; Labor rights; Dignity of the human person ; Universal Declaration of Human Rights; International Covenant on Economic, Social and Cultural Rights.

\section{INTRODUCCIÓN}

Como es bien sabido, lo que distingue los hombres de los animales es su capacidad de actuar sobre la naturaleza en orden a cambiar sus formas para hacerlas más acordes a sus necesidades de supervivencia. Este trabajo humano es realizado de forma consciente, con un propósito específico, gracias a la capacidad de abstracción y de representación simbólica inherente al hombre (BRAVERMAN, 1987, p. 61-62). Por consiguiente, como señala Rieznik (2004, p. 21), el trabajo es considerado una acción a propósito, guiada por la inteligencia, constituyéndose en un producto especial de la humanidad.

De forma genérica, el trabajo puede ser definido como toda acción humana realizada con gasto de energía física o mental, acompañada o no de auxilio instrumental, pero siempre dirigida a un fin determinado que no es otro sino producir efectos en el propio agente que la realiza, transformando el mundo (MARTINS FILHO, 2009, p. 3). Es con la realización de la actividad laboral que el hombre "fabrica la interminable variedad de cosas cuya suma total constituye el artificio humano", como afirmó Arendt (1993, p. 157).

Ahora bien, los hombres no pueden tener un precio y, por esa razón, no pueden ser utilizados únicamente como medio, es decir, como simples instrumentos para la producción de bienes por ningún otro hombre; ni siquiera por sí mismo. Eso porque el ser humano es un fin en sí mismo, y en esto consiste precisamente su dignidad, en virtud de la cual se elevan todas las cosas (KANT, 2007, p. 47-48).

Más contemporáneamente, Dworkin (1998, p. 305) definió la dignidad humana como el derecho del hombre a vivir en condiciones bajo las cuales sea posible el autorespeto, o sea, en un contexto sociocultural de existencia tal que le permita ser tratado de manera a no sentirse excluido de su comunidad. De ahí que ciertos derechos mínimos pasan a cobrar relieve para que se alcance efectivamente esas condiciones, pasándose a exigir una actitud proactiva de los Estados para garantizarlos.

En ese encuadre, al partir de la presuposición de que la dignidad debe ser el punto común de existencia entre todos los seres humanos, su preservación es lo que debe legitimar y R. Fac. Dir. UFG, v. 41, n.1, p. 141-162, jan. / jun. 2017

ISSN 0101-7187 
La Trascendencia de la Dignidad Humana en el Proceso de Reconocimiento Internacional de los Derechos Laborales

justificar la garantía de determinados derechos al trabajador. En este sentido, reflexiona Bonet Pérez (1999, p. 19) que quien ostenta la condición de trabajador, como ser humano que es, debe poder ejercer su actividad laboral de manera libre y con respeto de su propia personalidad y de sus derechos como individuo.

Con base en esa formulación, el jurista señala dos implicaciones muy importantes. La primera es el reconocimiento de que todos los trabajadores son titulares de unos derechos fundamentales, y que configuran la proyección de su dignidad humana en esta dimensión de su existencia. La segunda es la interrelación de estos derechos laborales fundamentales con la libertad del trabajador como ser humano, en cuanto manifestación de los derechos del individuo y de su libertad personal en el ámbito particular.

Al hilo de lo expuesto, parece ser que, en razón de las barbaries cometidas durante las dos Guerras mundiales, la sociedad internacional tomó una mayor consciencia de la importancia de garantizar los derechos laborales en el ámbito mundial, admitiendo, en definitiva, su naturaleza de derecho humano fundamental. Por consiguiente, esos dos fenómenos históricos, a par de tantos otros, acabaron por reforzar la importancia de desarrollarse con más ahínco una normativa internacional de protección de los derechos humanos a nivel universal que también pudiera resguardar la dignidad del trabajador.

\section{LA HISTORICIDAD DE LA DIGNIDAD COMO FUNDAMENTO DE LOS DERECHOS HUMANOS LABORALES}

Bobbio (1992, p. 5) ya señaló que los derechos humanos son derechos históricos, es decir, nacen gradualmente y no todos de una vez. Tampoco duran para siempre, sino que se imponen en determinadas circunstancias caracterizadas por luchas por la defensa de nuevas libertades contra viejos poderes.

Como subraya Sachs (1998, p. 156), los derechos humanos se conquistan, incluso muchas veces con barricadas, en un proceso histórico lleno de vicisitudes, por medio del cual las necesidades y las aspiraciones se articulan en reivindicaciones y en estandartes de lucha antes que se les reconozcan como derechos. En este mismo sentido, Herrera Flores (2000, p. IV) señala que los derechos humanos son "el conjunto de procesos normativos, institucionales y sociales que abren y consolidan espacios de lucha".

De acuerdo con Siqueira Junior (2007, p. 43): 
Os direitos humanos são aquelas cláusulas básicas, superiores e supremas que todo o individuo deve possuir em face da sociedade em que está inserido. São oriundos das reivindicações morais e políticas que todo ser humano almeja perante a sociedade e o governo. Nesse prisma, esses direitos dão ensejo aos denominados direitos subjetivos públicos, sendo em especial o conjunto de direitos subjetivos públicos que em cada momento histórico concretiza as exigências de dignidade, igualdade e liberdade humanas.

Por consiguiente, en cada momento histórico, las exigencias de la dignidad humana se ve concretada por un verdadero conjunto de facultades e instituciones que forman los derechos humanos, y que deben ser reconocidas positivamente por los ordenamientos jurídicos a nivel nacional e internacional (LUÑO, 2003, p. 48).

Sentado lo anterior, la necesidad de reconocimiento de los derechos humanos ganó importancia con el movimiento filosófico, literario y científico de la Ilustración, que ocurrió en Europa y en sus colonias a lo largo del siglo XVIII. Más allá de las teorías justificadoras de su exigencia que, en la práctica, poca importancia tenían, pugnas por su reconocimiento pudieron verse plasmadas en hechos como la Revolución Francesa y la Independencia de los Estados Unidos, que trajeron como idea central la dignidad de la persona humana como principio vectorial de un ordenamiento jurídico.

La Revolución Francesa constituyó innegablemente el más importante marco histórico para que los derechos humanos pudieran alcanzar el estatus de universalidad. Como ha reflejado al respecto Hobsbawm (2005, p. 85), aunque pueda ser considerada un fenómeno aislado, fue mucho más fundamental que cualquiera de las revoluciones sociales de masa que la precedieron y la siguieron, pues fue la única cuyas consecuencias fueron mucho más profundas y diferentes.

El resultado jurídico más inmediato de la Revolución Francesa, en su momento, fue la aprobación de la Declaración de los Derechos del Hombre y del Ciudadano, en 1789, que representó el fin del ancien régime, definiendo, por primera vez, los derechos personales y colectivos como universales ${ }^{1}$.

No obstante la existencia de una igualdad formal alcanzada por esos instrumentos, lo que se vislumbraba en la práctica era una desigualdad material proporcionada por el Estado liberal y que culminó en el surgimiento de muchas injusticias sociales, poniendo de relieve la insuficiencia de un reconocimiento solamente teórico de los derechos individuales y la necesidad del reconocimiento de derechos sociales, sobre todo, de cuño prestacional. 
La Trascendencia de la Dignidad Humana en el Proceso de Reconocimiento Internacional de los Derechos Laborales

La reivindicación por el reconocimiento de derechos sociolaborales se dio en la Revolución Industrial, por medio de movimientos sociales cuya inspiración fuera la política del welfare state, que ganó gran relieve después de la Primera Guerra mundial, siendo cristalizada en las Constituciones Mexicana de 1917, de Weimar e 1919, y en el Tratado de Versalles, igualmente de 1919. Como señala Truyol y Serra (2000, p. 30-31), si la burguesía liberal ascendente había logrado el reconocimiento jurídico-positivo de los derechos individuales de libertad, al proletariado hubo reivindicar derechos económicos y sociales.

Esos derechos fueron circunscritos al rol de derechos humanos pertenecientes a la segunda dimensión de derechos humanos, y fueron consagrados, principalmente, en la Declaración Universal de los Derechos Humanos (DUDH) y en el Pacto Internacional de Derechos Económicos, Sociales y Culturales (PIDESC) ${ }^{2}$, caracterizándose por exigir la intervención de los poderes estatales para su realización efectiva, por medio de prestaciones y servicios públicos e igualmente por reconocer muchos derechos de carácter sociolaboral, aunque también presenten elementos negativos como los derechos civiles y políticos.

\section{LA TRAYECTORIA DE RECONOCIMIENTO INTERNACIONAL DE LOS DERECHOS HUMANOS LABORALES}

\subsection{La Revolución Industrial y la reificación del trabajador}

La Revolución Industrial representó una transformación social de importancia indescriptible en el incipiente capitalismo del siglo XVIII, contribuyendo decisivamente a la modificación profunda de las relaciones sociales heredadas de las épocas anteriores al abrir espacio para la mecanización, proporcionando una separación definitiva entre los que detenían el capital y los que ejercían el trabajo. Según Doob (1975, p. 34), la Revolución Industrial representó:

[...] el momento de transición de una fase primitiva y todavía inmadura del capitalismo - en el que el régimen de la pequeña producción estaba siendo impregnado por el capital, subordinado a él, despejado de su independencia como forma de economía, pero que aún no había sido transformado enteramente - a una fase en que el capitalismo sobre la base del cambio técnico, realiza su propio específico proceso de producción de gran escala, la fábrica con lo que se consuma el proceso final de divorcio entre el productor y su propiedad sobre los medios de producción, (o lo que de ella le quedaba), y se establece una relación simple y directa entre capitalistas y obreros asalariados. 
Como no podría ser diferente, ese antagonismo económico acabó engendrando un grave enfrentamiento en el seno de la nueva sociedad capitalista. Los conflictos generados en el ámbito de las relaciones entre empleador y empleado acabaron por trascender el universo laboral, trayendo consecuencias que han afectado la vida social de los individuos, pues a pesar de una cuestionable igualdad formal que resultaba del pacto laboral realizado entre empleador y empleado ${ }^{3}$, en la práctica, la desigualdad era tremenda.

El obrero se veía obligado a la contratación laboral bajo condiciones miserables, justamente porque su condición personal social y económica no le dejaba otra alternativa para ganar el sustento. En este sentido, es muy ilustrativa la identificación hecha por Geremek (1998, p. 251) de que la pobreza se insería en el marco del desarrollo:

[...] la masa de la población obrera, creada como consecuencia de los procesos de proletarización en el campo y en las ciudades, era tratada como un espacio social de la indigencia. Las condiciones de vida cotidianas, la situación de las viviendas, el estado de salud, las familias numerosas, el aspecto exterior, así como los comportamientos sociales, constituían la base para una identificación entre obreros e indigentes. Las dimensiones de los procesos de proletarización resultan patentes por el hecho de que, en Francia, en torno a 1790, no menos del 40 por 100 de la población rural formaba parte del proletariado y del semiproletariado; en los centros urbanos, los obreros asalariados representaban, en aquel periodo, entre el 45 y el 60 por 100 de la población. Ciertamente la identificación entre obreros y pobres determinó que la proletarización confiriese al pauperismo una dimensión de masas.

Cualquier trabajador era bien venido, pues si antes, en muchos oficios, la fuerza del trabajador era un factor clave, a partir de entonces, la fuerza era realizada por las máquinas. Por esa razón que niños y mujeres pasaron a hacer parte de ese panorama deplorable, pues representaban lo que había de más barato en términos de mano de obra, como explican Pazzinato y Senise (1993, p. 177):

[...] o alto custo das máquinas e ferramentas industriais levava os empresários a utilizá-las intensivamente, a fim de recuperar os investimentos iniciais e obter lucros. Isto era feito mediante o emprego de uma mão-de-obra barata e numerosa, submetida a jornadas médias de trabalho de dezesseis horas por dia. Mulheres e crianças eram largamente empregadas, uma vez que sua remuneração era inferior à da mão-de-obra masculina.

En cuanto al régimen laboral, las medidas aplicadas a los trabajadores eran cada vez más drásticas, todo con vistas a evitar un comportamiento contrario al disciplinamiento necesario para el adecuado funcionamiento del sistema. La explotación del trabajo era nítida y se veía a través de las condiciones subhumanas en que la labor era desarrollada (largas 
La Trascendencia de la Dignidad Humana en el Proceso de Reconocimiento Internacional de los Derechos Laborales

jornadas de labor, prácticamente ininterrumpidas; locales mal alambrados y sin higiene; pagamentos muy bajos, etc.).

Acerca del régimen laboral emergente, Bauman (2000, p. 20) analiza que la nueva clase trabajadora, a diferencia de los siervos de la gleba del régimen feudal, había se tornado formalmente libre, careciendo de constreñimientos extraeconómicos para trabajar. Por lo tanto, potencialmente, estaban en condiciones de rechazar su incorporación al trabajo o la forma en la que se pretendía emplearlos. En este contexto, es posible identificar, según el autor, el disciplinamiento de la fuerza laboral como un conflicto de gran importancia:

El problema central que enfrentaban los pioneros de la modernización, era la necesidad de obligar a la gente - acostumbrada a darle sentido a su trabajo a través de sus propias metas, mientras retenía el control de las tareas necesarias para hacerlo - a volcar su habilidad y su esfuerzo en el cumplimiento de tareas que otros les imponían y controlaban, que carecían de sentido para ella. La solución al problema fue la puesta en marcha de una instrucción mecánica dirigida a habituar a los obreros a obedecer sin pensar, al tiempo que se los privaba del orgullo del trabajo bien hecho y se les obligaba a cumplir tareas cuyo sentido se les escapaba.

Como señala Hobsbawn (2005, p. 58), la disciplina laboral establecida era draconiana, constituyéndose un código de patronos y obreros que inclinaba la ley del lado de los primeros, sobre todo en la práctica, donde se retribuía tan escasamente al trabajador que este se veía obligado a laborar intensamente toda la semana para alcanzar unos salarios mínimos.

La escasa retribución salarial otorgada a los trabajadores y la precariedad generalizada de las condiciones de trabajo casi inhumanas eran la regla. De acuerdo con Otero y Grossi (2005, p. 231-233), los trabajadores vivían en situación de hacinamiento y las normas de higiene y seguridad más elementales eran ignoradas con el fin de abaratar los costos y ganar tiempo para la producción, afuera las extenuantes jornadas de trabajo que podían comenzar a las 4 horas de la mañana y terminar a las 10 horas de la noche.

Para ilustrar ese panorama, hay que destacar a continuación algunos trechos de un informe elaborado por Luis René Villerme sobre el estado físico y moral de los obreros franceses, de 1840, empleados en la manufactura de algodón, lana y seda:

El alto costo de los alquileres no permite a los obreros del algodón que ganan los más bajos salarios o que tienen más fuertes cargas de familia, alojarse en las proximidades de sus talleres [...]. De allí la necesidad que lo más pobres tienen que alojarse lejos de la ciudad, a una legua o legua y media, o aún más lejos [...]. Así la 
fatiga de una jornada ya desmesuradamente larga, puesto que es de al menos 15 horas, viene a agregarse para estos infelices, el tiempo que insume la ida y la vuelta tan frecuentes y penosas [...]. Los niños son empleados en las manufacturas de algodón de Alsacia desde la edad en que pueden comenzar a recibir el beneficio de la instrucción primaria, pero casi siempre resultan privados de ella [...]. Es difícil hacerse una idea del aspecto sucio y miserable de estas mujeres que están empleadas en la extracción de seda, así como la horrible suciedad de sus manos, del mal estado de salud de muchas de ellas y el olor nauseabundo, sui generis, que se desprende sus vestimentas, infesta los talleres y rechaza a quienes se acerca [...] (apud BARBAGELATA, 2009, p. 23).

Fue en aquellos momentos que surgió el movimiento obrero, con el objetivo de implementar condiciones mínimas de labor que pudieran atender a la dignidad de la persona humana. Como bien explican Gomes e Gottschalk (2005, p. 2), cuando los individuos son puestos en condiciones de vida semejantes, tienden siempre a asociarse, y con tanto más fuerza atractiva cuanto más precarias sean sus condiciones de existencia. En este mismo sentido, señala Pinto (2003, p. 25) que:

[...] essa aglutinação facultou aos trabalhadores uma intercomunicação, através da qual se abriu uma consciência coletiva em relação aos dois extremos de exploração a que eram submetidos: a péssima retribuição da energia pessoal utilizada e a utilização de sua força de trabalho em intensidade desmedida, que, associadas, levavam ao seu rápido esgotamento como unidade de produção e à sua quase total marginalização no gozo dos benefícios de conforto

A partir de esa percepción colectiva es que las movilizaciones y huelgas empezaron a surgir para poner fin a los abusos, sin cuestionar, no obstante, las bases del sistema. Esa toma de conciencia de la existencia de un problema o cuestión social alcanzó en la segunda mitad del siglo XIX una hondura y extensión hasta entonces inéditas, como subraya Melgar (2003, p. 81).

Como destacó Hobsbawm (2005, p. 64), es notable que las más serias consecuencias generadas por la industrialización fueron sociales. La transición de la nueva economía creó gran miseria y descontentamiento, dos ingredientes que contribuirían para la revolución social que sería llevada a cabo por los trabajadores de la industria y las poblaciones pobres de las ciudades, culminando en las revoluciones de 1848 en el continente europeo y en los amplios movimientos cartistas en Inglaterra.

La industrialización había hecho miserables los pequeños asalariados que eran cada vez más numerosos e indispensables, construyendo una clase social a que Marx acuñó de "proletariado". Ese momento fue llamado por la literatura de "pauperismo", para representar no sólo la miseria material sino que el estado de estigmatización moral en el cual quedaban 
La Trascendencia de la Dignidad Humana en el Proceso de Reconocimiento Internacional de los Derechos Laborales

prisioneros los pequeños trabajadores en la época (CASTEL, 2005, p. 30). Como resume Geremek (1998, p. 249), el pauperismo se había tornado conditio sine qua non para la producción capitalista.

3.2 La "cuestión social" y su teorización acerca del reconocimiento de la dignidad humana del trabajador

Cuando los efectos negativos de la Revolución Industrial se tornaron cada vez más factibles y gravosos, repercutiendo directamente sobre las condiciones generales de vida del trabajador y de su familia, diversos sectores de la sociedad pasaron a criticar el orden instaurado y proponer fórmulas para enfrentarla en búsqueda de un mundo más justo. Esos ideales desencadenaron movimientos de carácter socialista y anarquista, los cuales buscaban enunciar y alterar aquella situación deplorable. A esa problemática la llamaron "cuestión social".

Los primeros a reflejar sobre esa cuestión fueron los "socialistas utópicos", con una visión romántica de los nuevos tiempos y fórmulas transformadoras, proponiendo la creación de comunidades basadas en la razón y la justicia (valores que deberían estar por encima de la incesante búsqueda por ganancias). Sus principales representantes fueron Robert Owen, Henri de Saint-Simon y Charles Fourier.

En oposición a ellos, surgieron los llamados "socialistas científicos", más bien conocidos como marxistas, y que se pusieron a criticar duramente los planteamientos de los primeros. Su mayor teórico fue Karl Marx, cuya obra más conocida, "El Capital”, publicada en 1867, causó una revolución en la economía y en las ciencias sociales en general. Como señala Aron (1997, p. 135-136), su pensamiento es un análisis y una comprensión de la sociedad capitalista en su funcionamiento actual, en su estructura presente y en su devenir necesario; o aún, es una interpretación del carácter contradictorio o antagónico de la sociedad capitalista.

El marxismo sostiene que el conflicto capital-trabajo es estructural e insuperable en el marco del capitalismo, expresándose esta oposición principalmente en la apropiación que el capital hace del "plusvalor" producido por el obrero en su jornada de trabajo, lo que desencadena en la explotación del proletariado por la burguesía. En pocas palabras, el marxismo propone, mediante la dictadura del proletariado, la superación del capitalismo, el fin de la explotación, y la lucha de clases. 
Otra corriente ideológica de relieve surgida en el siglo XIX fue el Anarquismo, cuya idea principal giraba en torno a la supresión de toda forma de gobierno en defensa de una libertad general. Sus principales representantes teóricos fueron Pierre-Joseph Proudhon, Piotr Alexeyevich Kropotkin y Mikhail Bakunin.

En este orden de ideas, hay que subrayar que esa realidad actuó como el motor del cambio de mentalidad que se ha operado en el legislador europeo de la segunda mitad del siglo XIX, y que originó el denominado "reformismo social" y las primeras iniciativas para la consolidación de una legislación internacional del trabajo.

\subsection{El surgimiento del derecho laboral y su reconocimiento como un derecho humano}

Aunque existan reminiscencias antiquísimas de reglamentación del trabajo, como el antiguo reino de Babilonia, como advierte Gamonal (2008, p, 10), esas reglas están muy lejos de lo que se consolidó como derecho laboral en función del impacto causado por la Revolución Industrial y por el capitalismo en la sociedad de finales del siglo XIX. En aquellos momentos, se tornó imperioso responder a una urgencia de proteger a los trabajadores y asegurar la continuidad del sistema capitalista, por medio de un control del mercado y de una regulación de la utilización empresarial del trabajo (LOPEZ, 2004, p. 110).

Con el fin de la Primera Guerra mundial, se realizó en Paris, en 1919, la Conferencia de la Paz, que decidió sobre la creación de una Comisión de Legislación Internacional del Trabajo para estudiar, preliminarmente, la regulación internacional de la labor y determinar una manera de establecer una organización internacional perene entre los países. El objetivo que se planteaba era lo de facilitar una acción uniforme en cuanto a la regulación de las condiciones de trabajo.

En este mismo año fue redactado y aprobado por la Conferencia el texto que pasó a ser la decimotercera parte del Tratado de Versalles, en virtud del cual se creó la Organización Internacional del Trabajo, cuyas disposiciones están todavía vigentes y siguen haciendo parte de su Constitución. Se ha hecho figurar en la Sección II del Tratado, en su artículo 427, nueve principios que todas las comunidades industriales deberían implementar para la reglamentación de las condiciones de trabajo, y que deberían ser ampliados posteriormente, con la Declaración de Filadelfia de 1944.

Los nueve principios fueron los siguientes: Primero: El trabajo no debe considerarse meramente como una mercancía o artículo de comercio; Segundo: El derecho de asociación por razones lícitas tanto para trabajadores como empleadores; Tercero: El pago de R. Fac. Dir. UFG, v. 41, n.1, p. 141-162, jan. / jun. 2017 
La Trascendencia de la Dignidad Humana en el Proceso de Reconocimiento Internacional de los Derechos Laborales

un salario adecuado para el empleado, que le permita mantener un estándar de vida razonable, entendido esto en el contexto de su época y país; Cuarto: La adopción de 8 horas al día o 48 horas a la semana dirigida a donde esto no se haya aplicado todavía; Quinto: La adopción de un descanso semanal de, al menos, 24 horas, y debe incluir el domingo siempre que sea posible; Sexto: La abolición del trabajo infantil y la imposición de condiciones similares en el trabajo de personas jóvenes, para que puedan continuar con su educación para asegurar su adecuado desarrollo físico; Séptimo: Mujeres y hombres deben recibir igual remuneración para trabajo del igual valor; Octavo: El estándar establecido por las leyes de cada país respetando las condiciones de trabajo deben ser dictadas considerando un tratamiento económico equitativo para todos los trabajadores que residan legalmente en el mismo; y Noveno: Cada Estado debe aprovisionarse con un sistema de inspección donde deben participar mujeres, con el objetivo de asegurar el cumplimiento de las leyes y regulaciones para la protección de los empleados.

A partir de ese momento, varios instrumentos internacionales de gran relevancia empezaron a surgir, y el derecho laboral internacional rápidamente se institucionalizó en el mundo, cristalizándose en la mayoría de las constituciones occidentales. De acuerdo con Nascimento (2008, p. 34), la constitucionalización garantizó la libertad de asociación para la defensa y mejoría de las condiciones de trabajo y producción; permitió la participación del trabajador en el proceso político; reafirmó las normas sobre seguridad social; y promovió la integración del trabajador en la empresa y su derecho de participar en la fijación de sus sueldo y en las demás condiciones del trabajo.

Con la promulgación de la Constitución de Weimar fue dado el primer paso para que los ordenamientos constitucionales de los Estados modernos pasasen a incorporar esos preceptos laborales en sus textos ${ }^{4}$, mereciendo ser destacadas las legislaciones nacionales de Argentina, Australia, Estados Unidos de América, Francia, Italia ${ }^{5}$, Suecia, URSS y también de Brasil.

Hay que resaltar el hecho de que la legislación laboral, principalmente hasta el fin de la Segunda Guerra mundial, presentaba un carácter notablemente autoritario y corporativista, lo que reflejaba la gran parte de los regímenes políticos que se desarrollaron en Europa, especialmente el fascismo italiano (1921), el nazismo alemán (1933) y el franquismo español (1939). Todos esos regímenes se caracterizaron por una fuerte intervención del 
Estado en la esfera privada de las relaciones de trabajo, principalmente en la regulación y control de las relaciones colectivas de trabajo.

Sin embargo, terminada la Segunda Guerra mundial, en 1945, lo que se pasó a buscar fue una política laboral de libertad y de asociación, y de negociación colectiva de los conflictos de trabajo (MORAES FILHO, 1960, p. 89).

\section{LA CREACIÓN DE UNA NORMATIVA INTERNACIONAL DE CUÑO UNIVERSAL PARA LA PROTECCIÓN DE LOS TRABAJADORES}

Dentro de la fase evolutiva del derecho laboral que se refiere al período de 1919 hasta la década de 1970 es que fueron producidos los más importantes instrumentos de protección internacional de esos derechos. La idea era imponer a la sociedad internacional el reconocimiento de un verdadero núcleo duro de derechos laborales para alcanzar un nivel protección internacional de "mínimos", siempre que este nivel no existiera todavía en el ámbito interno de actuación de los Estados.

La DUDH y el PIDESC fueron los instrumentos responsables por la cristalización de ese núcleo duro fuera del ámbito específico de la OIT, imbuidos del espíritu del célebre discurso proferido en 1941 por el ex-presidente de los Estados Unidos, Franklin RoOsEVELT que, en su momento, destacaba, entre otros puntos, la importancia de que el Estado ofreciera una seguridad que permitiese al trabajador vivir exento de miedos en relación a las fuerzas económicas que le eran infinitamente superiores.

\subsection{La Declaración Universal de los Derechos Humanos (DUDH)}

De todos los instrumentos internacionales de protección de los derechos humanos, el más significativo, no solamente en la historia del desarrollo de la positivización de los derechos de protección al trabajador, sino que de todos los derechos humanos, es, sin duda, la DUDH, adoptada y proclamada en la Resolución 217 A (III) de la Asamblea General de las Naciones Unidas, de 10 de diciembre de 1948.

La DUDH representó mucho en la labor de promoción y defensa de los derechos humanos sociolaborales de la OIT. Como declaró la Comisión de Expertos en Aplicación de Convenios y Recomendaciones en el informe de su reunión de 1997, en los párrafos 56 a 58: 
La Trascendencia de la Dignidad Humana en el Proceso de Reconocimiento Internacional de los Derechos Laborales

\begin{abstract}
Las normas y actividades cumplidas en la práctica por la OIT en materia de derechos humanos están vinculadas estrechamente a los valores universales establecidos en la Declaración [...]. Las normas de la OIT en materia de derechos humanos, conjuntamente con los instrumentos adoptados en la ONU y en otras organizaciones internacionales, dan aplicación práctica a la expresión general e las aspiraciones humanas formuladas en la DUDH y han traducido en términos vinculantes los principios de ese noble documento" (OIT, 1998, p. 17).
\end{abstract}

Los artículos de la DUDH que atañen directamente a los derechos laborales son el 23 y el 24. De acuerdo con lo primero, toda persona tiene derecho al trabajo, a la libre elección de su trabajo, a condiciones equitativas y satisfactorias de trabajo y a la protección contra el desempleo, bien como a igual salario por trabajo igual, sin discriminación alguna.

Además, toda persona que trabaja tiene derecho a una remuneración equitativa y satisfactoria, que le asegure, así como a su familia, una existencia conforme a la dignidad humana y que será completada, en caso necesario, por cualesquiera otros medios de protección social. Por fin, el artículo 23 afirma que toda persona tiene derecho a fundar sindicatos y a sindicarse para la defensa de sus intereses, y el artículo 24 consagra el derecho al descanso, al disfrute del tiempo libre, a una limitación razonable de la duración del trabajo y a vacaciones periódicas pagadas.

Con la DUDH, tuvo inicio una fase en la cual la afirmación de los derechos pasa a ser, al mismo tiempo, universal y positivizada. Universal en el sentido de que los destinatarios de los principios en ella convertidos no son más solamente los ciudadanos de este o aquél país, pero toda la humanidad; y positiva porque pone en movimiento un proceso que objetiva que los derechos humanos no sean simplemente proclamados o solamente reconocidos en el plano teórico, sino también efectivamente protegidos, hasta mismo en contra del propio Estado que los haya violado.

Como señalan Sohn y Buergenthal (1973, p. 516), la Declaración se distinguió de las tradicionales cartas de derechos humanos de los siglos XVIII y XIX y comienzos del siglo $\mathrm{XX}$ que traían diversas normas fundamentales y constitucionales, en la medida en que no consagraba solamente derechos civiles y políticos, sino que también derechos económicos, sociales y culturales, como el derecho del trabajo.

De acuerdo con Piovesan (2012, p. 46-47), al conjugar el valor de la libertad con el valor de la igualdad, la Declaración define una nueva concepción de derechos humanos, concebidos, a partir de entonces, como una unidad interdependiente, interrelacional e indivisible: 
[...] sem a efetividade dos direitos econômicos, sociais e culturais, os direitos civis e políticos se reduzem a meras categorias formais, enquanto que, sem a realização dos direitos civis e políticos, ou seja, sem a efetividade da liberdade entendida em seu mais amplo sentido, os direitos econômicos, sociais e culturais carecem de verdadeira significação. Não há mais como cogitar da liberdade divorciada da justiça social, como também infrutífero pensar na justiça social divorciada da liberdade. Em suma, todos os direitos humanos constituem um complexo integral, único e indivisível, em que os diferentes direitos estão necessariamente interrelacionados e são interdependentes entre si.

La DUDH, como subraya Trindade (1999, p. 26), contribuyó decisivamente para la incidencia de la dimensión de los derechos humanos tanto en el ámbito internacional como en lo del derecho interno, vislumbrándose una abstracción de la fragmentación tradicional entre esos dos ordenamientos jurídicos, lo que promovió una constante interacción en beneficio de todos los seres humanos por fuerza de las disposiciones de los tratados de derechos humanos.

Es interesante notar que la DUDH, a pesar de no haber sido adoptada por un acto jurídico vinculante, se estableció como uno de los parámetros fundamentales utilizados por la sociedad internacional para deslegitimar cualquier actuación gubernamental de un Estado que vulnerase la normativa establecida en su seno. Así que, al menos teóricamente, si un Estado es violador de derechos humanos, no deberá ser merecedor de la aprobación por los demás Estados, como señala Cassesse (1990, p. 46-47).

Con el diseño del proyecto de la Declaración, en 1946, ya se planteó cuál sería la manera más eficaz de asegurar la observancia internacional de los derechos en ella previstos, prevaleciendo el entendimiento de que la DUDH debería ser positivizada bajo la forma de tratado internacional, para que fuera jurídicamente obligatoria y vinculante. De ahí que, después de dieciocho años, fueron elaborados los dos tratados internacionales que pasarían a incorporar, con mayor precisión y detalles los derechos en ella constantes: el PIDCP y el PIDESC.

\subsection{El Pacto Internacional de Derechos Económicos, Sociales y Culturales (PIDESC)}

En 16 de diciembre de 1966, la Asamblea General de la ONU, en su Resolución 2200 A (XXI), adoptó concomitantemente los dos Pactos señalados. El PIDCP trajo, de forma muy genérica, menciones a temas de orden económico y social, mereciendo especial referencia, en el ámbito de los derechos sociolaborales, el artículo 22 que reconoce el derecho de toda persona a "asociarse libremente con otras, incluso el derecho de fundar sindicatos y 
La Trascendencia de la Dignidad Humana en el Proceso de Reconocimiento Internacional de los Derechos Laborales

afiliarse a ellos para defender sus intereses", desde que estén sujetos a las restricciones previstas por ley.

A su vez, el PIDESC reconoció en su artículo $7^{\circ}$ el derecho de toda persona al goce de condiciones de trabajo equitativas y satisfactorias que le aseguren en especial, una remuneración que proporcione, como mínimo, un salario equitativo e igual por trabajo de igual valor (sin distinciones de ninguna especie), asegurando a las mujeres condiciones de trabajo no inferiores a las de los hombres (con salario igual por trabajo igual), y condiciones de existencia dignas para ellos y para sus familias:

Los Estados Partes en el presente Pacto reconocen el derecho de toda persona al goce de condiciones de trabajo equitativas y satisfactorias que le aseguren en especial: a) Una remuneración que proporcione como mínimo a todos los trabajadores: i) Un salario equitativo e igual por trabajo de igual valor, sin distinciones de ninguna especie; en particular, debe asegurarse a las mujeres condiciones de trabajo no inferiores a las de los hombres, con salario igual por trabajo igual; ii) Condiciones de existencia dignas para ellos y para sus familias conforme a las disposiciones del presente Pacto; b) La seguridad y la higiene en el trabajo; c) Igual oportunidad para todos de ser promovidos, dentro de su trabajo, a la categoría superior que les corresponda, sin más consideraciones que los factores de tiempo de servicio y capacidad; d) El descanso, el disfrute del tiempo libre, la limitación razonable de las horas de trabajo y las variaciones periódicas pagadas, así como la remuneración de los días festivos.

El mismo artículo buscó garantizar la seguridad y la higiene en el trabajo; igual oportunidad para todos de ser promovidos a una categoría superior (sin más consideraciones que los factores de tiempo de servicio y capacidad); el descanso, el disfrute del tiempo libre, la limitación razonable de las horas de trabajo; y las variaciones periódicas pagadas, así como la remuneración de los días festivos. El artículo $8^{\circ}$ trató del comprometimiento que los Estados Partes deberían tener en garantizar un conjunto mínimo de normas jurídicas que regularan el derecho colectivo del trabajo:

1. Los Estados Partes en el presente Pacto se comprometen a garantizar: a) El derecho de toda persona a fundar sindicatos y a afiliarse al de su elección, con sujeción únicamente a los estatutos de la organización correspondiente, para promover y proteger sus intereses económicos y sociales. No podrán imponerse otras restricciones al ejercicio de este derecho que las que prescriba la ley y que sean necesarias en una sociedad democrática en interés de la seguridad nacional o del orden público, o para la protección de los derechos y libertades ajenos; b) El derecho de los sindicatos a formar federaciones o confederaciones nacionales y el de éstas a fundar organizaciones sindicales internacionales o a afiliarse a las mismas; c) El derecho de los sindicatos a funcionar sin obstáculos y sin otras limitaciones que las que prescriba la ley y que sean necesarias en una sociedad democrática en 
interés de la seguridad nacional o del orden público, o para la protección de los derechos y libertades ajenos; d) El derecho de huelga, ejercido de conformidad con las leyes de cada país. 2. El presente artículo no impedirá someter a restricciones legales el ejercicio de tales derechos por los miembros de las fuerzas armadas, de la policía o de la administración del Estado. 3. Nada de lo dispuesto en este artículo autorizará a los Estados Partes en el Convenio de la Organización Internacional del Trabajo de 1948 relativo a la libertad sindical y a la protección del derecho de sindicación a adoptar medidas legislativas que menoscaben las garantías previstas en dicho Convenio o a aplicar la ley en forma que menoscabe dichas garantías".

Hay que destacar en el PIDESC el derecho a la libre fundación de sindicatos y de afiliación, con sujeción únicamente a los estatutos de la organización correspondiente, para promover y proteger sus intereses económicos y sociales. De este modo, no se podrían imponer otras restricciones al ejercicio de ese derecho que las que prescriba la ley, y desde que sean necesarias, en una sociedad democrática, para proteger el interés de la seguridad nacional o el orden público, o para la protección de los derechos y libertades ajenos.

Tratando aún del derecho sindical, el PIDESC previó el derecho de los sindicatos a formar federaciones o confederaciones nacionales, y de éstas a fundar organizaciones sindicales internacionales o a afiliarse a las mismas, bien como de funcionar sin obstáculos y sin otras limitaciones, a la excepción de las señaladas en el párrafo anterior.

El derecho de huelga vino igualmente tratado en ya referido artículo $8^{\circ}$, trayendo de antemano la limitación a su ejercicio de conformidad con las leyes de cada país y la advertencia de que dicho artículo no impedirá someter a restricciones legales el ejercicio de tales derechos por los miembros de las fuerzas armadas, de la policía o de la administración del Estado, garantizándose, de esta manera, el pleno ejercicio de la soberanía a todos los que vendrían a firmarlo e incorporarlo a sus ordenamientos jurídicos internos.

\subsubsection{El Comité de Derechos Económicos, Sociales y Culturales (CDESC)}

Hay que poner de relieve que el PIDESC presentó una peculiar sistemática de control e implementación de los derechos que contempla, incluyéndose en ella el mecanismo de informes que los Estados Parte se comprometen a presentar. Así que, en 1985, fue creado el Comité de Derechos Económicos, Sociales y Culturales (CDESC), un órgano de la ONU compuesto por expertos independientes en materia de derechos humanos, y conformado por 18 miembros que actúan a título personal, y que se encargan de supervisar el cumplimiento del PIDESC.

El CDESC se encuentra facultado para recibir y examinar informes que le presentan periódicamente los Estados Partes acerca de la forma cómo aplican y dan R. Fac. Dir. UFG, v. 41, n.1, p. 141-162, jan. / jun. 2017 
La Trascendencia de la Dignidad Humana en el Proceso de Reconocimiento Internacional de los Derechos Laborales

cumplimiento al PIDESC, emitiendo observaciones generales finales y recomendaciones, con la finalidad de proporcionar a los Estados algunos consejos prácticos y alentarlos a que adopten medidas adecuadas para la consecución de los derechos contemplados en el PIDESC. Además, el CDESC publica observaciones que tienen por objetivo interpretar las disposiciones del PIDESC.

En 10 de diciembre de 2008, por medio de la Resolución A/RES/63/117, fue finalmente adoptado el Protocolo Facultativo del PIDESC, que entró en vigor el 5 de mayo de 2013, y sumó un nuevo valor a la función de monitoreo del CDESC, en la medida en que proporcionó un mecanismo de exigibilidad y acceso a medios de reparación (un procedimiento que busca justicia y compensación) para las violaciones de los DESC, permitiéndole evaluar las quejas individuales de violaciones.

Según Riquelme Cortado (2012, p. 23), la coherencia con el sistema de Naciones Unidas y la complementariedad, confirmada en la práctica, entre sus dos principales funciones (examen de los informes periódicos de los Estados y de comunicaciones presentadas por particulares), avalaban la capacidad del Comité para llevar a cabo una investigación más profunda de casos concretos y tangibles, inexistente de otra manera.

El artículo 2 estableció la competencia del CDESC para recibir comunicaciones de personas o grupos de personas que se encuentren bajo la jurisdicción de un Estado parte y que aleguen ser víctimas de una violación de cualquiera de los derechos económicos, sociales y culturales enunciados en el Pacto por ese mismo Estado.

Merece la pena subrayar que el Comité no examinará una comunicación sin antes haberse cerciorado de que se hayan agotado todos los recursos disponibles en la jurisdicción interna, a la excepción de cuando la tramitación de esos recursos se prolongue injustificadamente (artículo 3), y, antes de pronunciar sobre el fondo de la comunicación, el Comité podrá dirigir a dicho Estado interesado, en cualquier momento, a los fines de su urgente examen, una solicitud para que adopte las medidas provisionales que sean necesarias en circunstancias excepcionales a fin de evitar posibles daños irreparables a la víctima o las víctimas de la supuesta violación (artículo 5).

A menos que el Comité considere que una comunicación es inadmisible, sin remisión al Estado parte interesado pondrá en su conocimiento, de forma confidencial, toda comunicación que reciba con arreglo al presente Protocolo. El Estado parte receptor, a su vez, presentará al Comité, por escrito, en un plazo de seis meses, explicaciones o declaraciones en 
que aclare la cuestión, indicando, en su caso, las medidas correctivas que haya adoptado (artículo 6).

En lo que concierne al examen de las comunicaciones, en los términos del artículo 8, el CDESC examinará en sesiones privadas las comunicaciones que reciba de personas o grupos a la luz de toda la documentación que se haya puesto a su disposición, siempre que esa documentación sea transmitida a las partes interesadas.

Para ello, podrá consultar, según convenga, la documentación pertinente que proceda de otros órganos, organismos especializados, fondos, programas y mecanismos de ONU y de otras organizaciones internacionales, incluidos los sistemas regionales de derechos humanos, y cualesquiera observaciones y comentarios del Estado parte interesado. El Comité considerará hasta qué punto son razonables y efectivas las medidas por el adoptadas.

El procedimiento de investigación se inicia, según el artículo 11, con el recibimiento de la información fidedigna que da cuenta de violaciones graves o sistemáticas por un Estado parte de cualesquiera de los derechos económicos, sociales y culturales enunciados en el Pacto, invitándole el CDESC a colaborar en el examen de la información y, a esos efectos, a presentar sus observaciones sobre dicha información. La investigación será de carácter confidencial y se solicitará la colaboración del Estado parte en todas las etapas del procedimiento.

El Comité, tomando en consideración las observaciones que haya presentado el Estado parte interesado - así como cualquier otra información fidedigna puesta a su disposición - podrá encargar a uno o más de sus miembros que realice una investigación inclusive una visita a su territorio - y presente con carácter urgente un informe al CDESC. Tras examinar las conclusiones de la investigación, las transmitirá al Estado parte interesado junto con las observaciones y recomendaciones que estime oportunas.

En un plazo de seis meses, después de recibir los resultados de la investigación y las observaciones y recomendaciones que le transmita el Comité, el Estado parte interesado presentará sus propias observaciones al Comité. Y cuando hayan concluido las actuaciones relacionadas con una investigación, el Comité podrá, tras celebrar consultas con dicho Estado, tomar la decisión de incluir un resumen de los resultados del procedimiento en su informe anual. Transcurrido ese período, el CDESC podrá, si es necesario, invitarle a que le informe sobre las medidas que haya adoptado como resultado de la investigación

En este contexto, hay que subrayar que, a pesar de los esfuerzos de las organizaciones de la sociedad civil, Brasil todavía no ha firmado el PF-PIDESC, lo que solo R. Fac. Dir. UFG, v. 41, n.1, p. 141-162, jan. / jun. 2017 
La Trascendencia de la Dignidad Humana en el Proceso de Reconocimiento Internacional de los Derechos Laborales

demuestra su omisión en lo que atañe al respeto a la garantía de los derechos humanos económicos, sociales y culturales, y su postura incoherente referente a lo que los gobiernos afirman internacionalmente y lo que de hecho hacen en términos de derechos humanos.

\section{CONCLUSIÓN}

Como se ha analizado, las barbaries cometidas en las Guerras mundiales reforzaron la importancia de desarrollar con más ahínco una normativa internacional de protección de los derechos humanos de ámbito universal y que, por supuesto, incluyó a los derechos laborales como esenciales para promover y resguardar la dignidad de la persona humana.

La importancia del reconocimiento internacional de instrumentos de protección al trabajador sigue siendo primordial en los días de hoy para el mantenimiento del catálogo de garantías y derechos mínimos obligatorios ya conquistados a lo largo de los años, e igualmente para el alcance de nuevos derechos, en un momento histórico en que las relaciones laborales toman nuevas formas (teletrabajo, home office, etc.) y la preservación de la dignidad del trabajador puede, consecuentemente, verse amenazada.

Hay que hacer notar que, a partir de los años 70, hubo un pulverización del soporte estable creado en la década de los 60 y que consolidó la condición de trabajador como sujeto protegido por el Estado. Con eso, se desestabilizó su condición de trabajador y la propia garantía de preservación de su dignidad, frente al desempleo de masas, la precarización de las condiciones del trabajo, y, paralelamente, al debilitamiento de las protecciones brindadas que dieron lugar a que un gran número de trabajadores se tornasen aún más vulnerables.

De lo expuesto, se aduce que, actualmente, la gran cuestión en torno a los derechos humanos laborales parece ser reafirmar la centralidad del trabajo, desde una perspectiva de conjunto (empleado, empleador, sociedad y Estado), pugnándose por una protección que sea efectiva, empleando las herramientas jurídicas más apropiadas para favorecerlos y resguardarlos.

Partiéndose del razonamiento de que el Derecho del Trabajo es un derecho humano social y, como tal, exige por parte del Estado una prestación, el punto de interés 
acaba por direccionarse más hacia el reconocimiento de las normas laborales ya existentes, que hacia su ampliación.

En este contexto, hay que recordar que la idea de establecer derechos mínimos para que sean cumplidos por toda la sociedad internacional tiene que ser compatibilizada con la soberanía de cada Estado que, en última instancia, decide si quiere o no adoptar un tratado internacional, e incorporarlo posteriormente a su ordenamiento jurídico interno. Desde esa perspectiva, es cierto que la soberanía pueda fácilmente convertirse en una excusa irrefutable de los Estados frente a cualquier intento de obligatoriedad de hacer aprobar e incorporar a su ordenamiento jurídico interno normas de protección a los derechos humanos laborales emanadas del Derecho Internacional.

En cualquier caso, cumple repetir que el Derecho del Trabajo es un derecho humano, y, por lo tanto, se le considera un derecho histórico. Además, hay que señalar que la dignidad está siempre relacionada a la progresión de las condiciones sociales del individuo y, si así es, los derechos laborales deben siempre progresar en la medida que las necesidades sociales vayan avanzando y nuevas prioridades vayan ganando relieve.

\section{REFERENCIAS}

ARENDT, Hannah. La condición Humana. Barcelona: Paidós, 1993.

ARON, Raymond. As etapas do pensamento sociológico. São Paulo: Martins Fontes, 1997.

BARBAGELATA, Héctor-Hugo. Curso sobre la evolución del pensamiento juslaboralista. Montevidéu: Fundación de Cultura Universitaria. 2009.

BAUMAN, Zygmunt. Trabajo, consumismo y nuevos pobres. Barcelona: Gedisa, 2000.

BRAVERMAN, Harry. Trabajo y Capital Monopolista. 8. ed. México: Nuestro Tiempo, 1987.

CASTEL, Robert. El proceso de individualización: fragilización de los soportes de identidad frente a las transformaciones del capital y del trabajo. In: SOSTO, Guillermo Pérez (coord.). Las manifestaciones actuales de la cuestión social. Buenos Aires: Instituto Di Tella, 2005, p. 27-34.

DOOB, Maurice. Estudios sobre el desarrollo del capitalismo. Buenos Aires: Siglo XXI, 1975. 
La Trascendencia de la Dignidad Humana en el Proceso de Reconocimiento Internacional de los Derechos Laborales

GAMONAL, Sergio. Fundamentos de Derecho Laboral. Santiago de Chile: Legal Publishing, 2008.

GEREMEK, Bronislaw. La piedad y la horca: historia de la miseria y de la caridad en Europa. Madrid: Alianza Editorial, 1998.

GOMES, Orlando, GOTTSCHALK, Élson. Curso de Direito do Trabalho. 17. ed. Rio de Janeiro: Forense, 2005.

HOBSBAWM, Eric. A Era das revoluções: Europa 1789-1848. 19. ed. São Paulo: Paz e Terra, 2005.

LOPEZ, Diego. Derechos, Trabajo y Empleo. Santiago de Chile: LOM Ediciones, 2004.

LUÑO, Antonio Enrique Pérez. Derechos Humanos, Estado de Derecho y Constitución. 8. ed. Madrid: Tecnos, 2003.

MARTINS FILHO, Ives Gandra da Silva. Manual de Direito e Processo do Trabalho. 18. ed. São Paulo: Saraiva, 2009.

MELGAR, Alfredo Montoya. El Reformismo Social en los orígenes del Derecho del Trabajo. Revista del Ministerio de Trabajo e Inmigración: Derecho del Trabajo: Centenario del Instituto de Reformas Sociales. Madrid: Subdirección General de Información Administrativa y Publicaciones del Ministerio de Trabajo e Inmigración, 2003, número extraordinario 1, p. 81-108.

MORAES FILHO, Evaristo de. Tratado Elementar de Direito do Trabalho. Rio de Janeiro: Freitas Bastos, 1960, vol 1.

NASCIMENTO, Amauri Mascaro. Curso de Direito do Trabalho: história e teoria geral do direito do trabalho: relações individuais e coletivas do trabalho. 23. ed. São Paulo: Saraiva, 2008.

OTERO, Arístides Silva, GROSSI, Mariela Mata de. La llamada Revolución Industrial: siglos XVIII y XIX. Caracas: Editorial Universidad Católica Andrés Bello, 2005.

PAZZINATO, Alceu Luiz, SENISE, Maria Helena Valente. História Moderna e Contemporânea. São Paulo: Ática, 1993.

PINTO, José Augusto Rodrigues. Curso de direito individual do trabalho: noções fundamentais de direito do trabalho, sujeitos e instituto do direito individual. 5. ed. São Paulo: LTr, 2003.

RIEZNIK, Pablo. Las Formas del Trabajo y la Historia. 2. ed. Buenos Aires: Biblos, 2004.

SWEEZY, Paul. Teoría del Desarrollo Capitalista. 7. ed. México. Fondo de Cultura Económica, 1973. 


\section{Marcio Morena PINTO}

${ }^{1}$ Aunque no se pueda negar su importancia como marco definidor de la universalidad de los derechos humanos, hay que destacar tres grandes instrumentos previos importantes para el reconocimiento de los derechos humanos, surgidos en los siglos XVI y XVII: la Petition of Right, de 1628, el Acta de Habeas Corpus, de 1679, y la Declaración de los Derechos (Declaration of Rights), de 1689, que resultó de la Revolución Gloriosa de Inglaterra. Igualmente, se puede citar como marco histórico las Declaración de Virginia, de 1776.

2 Aunque, hay que señalar que el origen histórico del reconocimiento de los derechos establecidos el Pacto se desprende de acontecimientos nacionales e internacionales anteriores, como subraya Cid (1993, p. 1).

${ }^{3}$ Tal como apunta Swezzy (1973, p. 49), los dos sujetos que componían la relación laboral eran considerados en un plano de igualdad perfecta, pues sus relaciones mutuas no eran relaciones entre amo y siervo de régimen de un status personal, sino relaciones contractuales entre seres humanos libres e iguales.

${ }^{4}$ Como es el caso, por ejemplo, de las constituciones de México (1917 y 1962), Chile (1925), Austria (1925), Rusia (1918 y 1935), España (1931), Perú (1933), Brasil (1934, 1937, 1946, 1967, 1969 y 1988), Uruguay (1934), Bolivia (1938), Nicaragua (1939), Honduras (1936), Colombia (1936 e 1945), República Federal Alemana (1949), República Democrática Alemana (1949), Romania y Checoslovaquia (1948), Venezuela (1947 y 1961), Turquía (1961), Yugoslavia (1921 y 1963) y Guatemala (1965).

${ }^{5}$ Como apunta Nascimento (2008, p. 34), la "Carta del Lavoro", editada en 1927 por Mussolini, se ha convertido en un documento fundamental del corporativismo peninsular y de las directrices que se establecerían para un orden político y laboral centralizado segundo en una fuerte interferencia estatal.

Artigo recebido em 10 de março de 2016 e aceito em 23 de junho de 2017 